Research Journal of Applied Sciences 13 (3): 202-208, 2018

ISSN: $1815-932 \mathrm{X}$

(C) Medwell Journals, 2018

\title{
Development of Methods to Determine Output Production Coefficient
}

\author{
Dmitry Nikolaevich Ligotsky and Kristina Vladimirovna Mironova \\ Saint Petersburg Mining University, 21 Line V.O. 2, 199106 Saint Petersburg, Russia Federation
}

\begin{abstract}
The output production coefficient is a coefficient of mineral deposit which shows calculation ratio of the volume of mineral product to the volume of mine rock mass during a certain production period. In this study, we describe the methods to determine the output production coefficient for complex deposits. The solution of the task allows to optimize parameters of current plans of open mine rock works and will define the mode of mine work. Besides this coefficient will give some more detailed information about resources of opencast mine and its vulnerability. The calculation of this value characterizes the research of this opencast mine as a local criterion. In this connection, the task to develop some methods of the determination of output production coefficient is our current task for today.
\end{abstract}

Key words: Mineral deposit, volume of mine rock mass, the inter-ramp angle, working bench, opencast mine, planned mode, the operational extraction coefficient, output production coefficient

\section{INTRODUCTION}

The study is a tribute to Henry Alexandrovich Holodnyakov, the Professor of Saint-Petersburg Mining University (Russia), one of the leading scientist and specialist in the field of engineering and complex open deposit development. The problem of scientific planning of mining work was developed in researches of many Soviet and Foreign scientists-miners.

Rzhevskiy (Member of the Academy of Sciences) defined the mode of mining work as "carrying out overburden and extraction work on opencast mine which provides planned safe and economically effective field development during the lifetime of the opencast mine".

There is a difference between a mine work mode and a calendar plan. The latter is made up according to common essential schemes of overburden and development systems but the choice of mine work mode allows for research of some versions of a calendar plan.

When we say a "calendar plan" we understand it as a definite distribution of mineral deposits volumes and mine mass in years of development. We distribute it this way due to one of the chosen modes of mine work.

After analyzing all details of mine work mode Rzhevskiy points at the most important factor which must be taken into consideration when making a project of opencast mines. This factor is the economical basis of the mode of mine work and in particular the overburden. He came to the conclusion that it was necessary to level off the volumes of overburden work because it "contributes to the stable economical industrial operation, uniform and better usage of the equipment and staff and it prevents the factory from increasing dramatically the number of facilities and personnel which later become not necessary".

There is a certain order how to fulfil works to extract mine mass on an opencast mine and this is a mode of mine work in case of development of complex mining fields. This will provide planned deposits extraction along with safe low-waste and economically effective development of mining fields throghout the existence of the opencast mine.

Along with the provision of uniform working mode of mine mass extraction we should also have the uniform extraction mode of all deposits which are the constituents of the complex mining field. There is a problem of levelling off coefficients of mineral deposit extraction.

We can level off the extraction by regulating the direction and order of mine work development or by decreasing the efficiency of an opencast mine where one kind of mineral deposits is extracted. The constant value of coefficient means running value of inter-ramp angles in different periods of the opencast mine work.

An opencast mine loading face is a loading face made up of only working benches. It means a bench

Corresponding Author: Dmitry Nikolaevich Ligotsky, Saint Petersburg Mining University, 21 Line V.O. 2, 199106 Saint Petersburg, Russia Federation 
on which mine works have not been finished (Yakubovskiy et al., 2015; Kholodjakov and Argimbaev, 2014).

\section{MATERIALS AND METHODS}

The inter-ramp angle $\varphi$ is determined as an angle of hade to the horizontal plane going through the bottom edge of lower and upper working benches of the opencast mine. For the opencast mine with the same width of working areas (B) as well as height (h) and inter-ramp angles $(\alpha)$ the width of working areas in modern opencast mines is from $25-100 \mathrm{~m}$ and is determined by a common technology and mine work organization. Consequently inter-ramp angle is $5-20^{\circ}$ but in most cases $10-12^{\circ}$ :

$$
\operatorname{tg} \varphi=\frac{h}{h \operatorname{ctg} \alpha+B}
$$

While using the opencast mine the position of a working bench and its inter-ramp angle changes all the time.

We shall see how the opencast mine shape will change depending on the depth of mine work at constant speed if the work is carried out at the constant inter-ramp angle. Deepening work takes place along the bench on the side of bottom wall of a main deposit where openings to surface are located after opening by means of internal end cuts (Fig. 1). During the process of opening and preparing underlying Bank ( $\mathrm{B}_{\mathrm{T}}$ width of initial cut at the Bottom) the working bench of the opencast mine moves downwards seizing more and more new banks. By doing so, we can observe the change of both the quantity of operating banks and the ratio of volumes of products and mine mass taken out (Argimbaev and Kholodjakov, 201; Pikalov et al., 2016; Argimbaev et al., 2015; Yakubovskiy et al., 2015; Kholodnyakov and Argimbayev, 2014; Pashkevich and Petrova, 2015).

Taking into consideration the volumes of deposits and mine mass taken out during field mining we can get the results given in Table 1 .

Table 1 that after deepening the opencast mine the volumes of mine mass cutting increase and reach maximum at the moment when the working bench approached the upper end circuit of the opencast mine on the surface (when deepening the mine work lower than mine 4 (Fig. 1). When deepening the work lower than mine 4 the volume of mine mass reduces (Yakubovskiy et al., 2014; Argimbaev and Yakubovskiy, 2014; Kholodjakov and Argimbaev, 2014; Argimbaev and Kholodjakov, 2013, 2016; Bukhman et al., 1966).

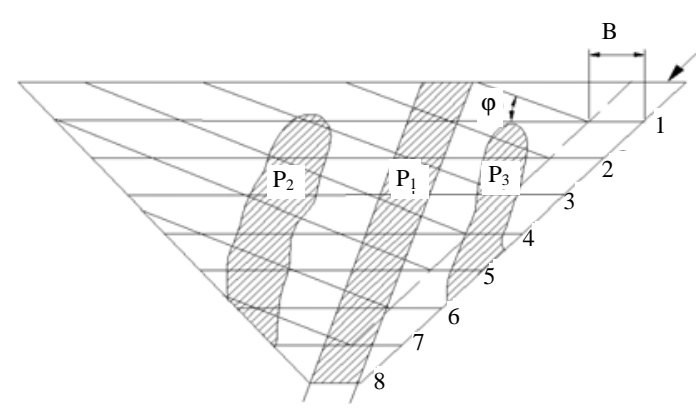

Fig. 1: The location change of the line of a working bench slope after deepening the mine work

Table 1: Calculation of volumes of mineral deposits and mine mass taken out while deepening the opencast mine

Volume $\left(\mathrm{mln} . \mathrm{m}^{3}\right)$ at the inter-ramp angle

\begin{tabular}{|c|c|c|c|c|c|}
\hline \multirow{3}{*}{$\begin{array}{l}\text { Working } \\
\text { deposits depth } \\
\text { (horizon) }\end{array}$} & \multicolumn{5}{|c|}{ Volume $\left(\mathrm{mln} \cdot \mathrm{m}^{3}\right)$ at the inter-ramp angle } \\
\hline & \multirow{2}{*}{$\begin{array}{l}\text { Mine } \\
\text { mass }\end{array}$} & \multirow{2}{*}{$\begin{array}{c}\text { Main } \\
\text { mineral } \\
\text { deposit }\left(\mathrm{p}_{1}\right)\end{array}$} & \multirow{2}{*}{$\begin{array}{l}\text { Operating } \\
\text { ratio of main } \\
\text { mineral } \\
\text { extraction }\end{array}$} & \multicolumn{2}{|c|}{$\begin{array}{l}\text { Secondary } \\
\text { mineral deposits }\end{array}$} \\
\hline & & & & $\mathrm{P}_{2}$ & $\mathrm{P}_{3}$ \\
\hline \multicolumn{6}{|l|}{$\varphi=15^{0}$} \\
\hline 1 & 12.9 & 0.3 & 0.02 & - & - \\
\hline 2 & 32.0 & 4.7 & 0.15 & - & 1.7 \\
\hline 3 & 50.6 & 4.7 & 0.09 & 3.2 & 6.2 \\
\hline 4 & 64.0 & 4.7 & 0.07 & 8.2 & 4.5 \\
\hline 5 & 54.0 & 4.7 & 0.08 & 6.6 & 4.3 \\
\hline 6 & 39.5 & 4.7 & 0.12 & 6.7 & 2.7 \\
\hline 7 & 24.5 & 4.4 & 0.18 & 5.8 & - \\
\hline 8 & 10.5 & 3.8 & 0.36 & 2.0 & - \\
\hline $\begin{array}{l}\text { Total } \\
\varphi=0^{0}\end{array}$ & 288.0 & 32.0 & - & 31.5 & 19.4 \\
\hline 1 & 64.0 & 4.0 & 0.06 & - & - \\
\hline 2 & 56.0 & 4.0 & 0.07 & 5.9 & 3.9 \\
\hline 3 & 48.0 & 4.0 & 0.08 & 6.6 & 4.8 \\
\hline 4 & 40.0 & 4.0 & 0.10 & 5.9 & 4.5 \\
\hline 5 & 32.0 & 4.0 & 0.12 & 5.8 & 4.8 \\
\hline 6 & 24.0 & 4.0 & 0.17 & 5.3 & 1.4 \\
\hline 7 & 16.0 & 4.0 & 0.25 & 2.0 & - \\
\hline 8 & 8.0 & 4.0 & 0.50 & - & - \\
\hline Total & 288.0 & 32.0 & - & 31.5 & 19.4 \\
\hline
\end{tabular}

Operational coefficient of extraction will constantly change with respect to such order and its change for the main deposit will be characterized by the curve $\mathrm{K}_{\mathrm{p}}$ shown in Fig. 2.

The similar change of extraction coefficients influences the opencast mine work. The main difficulties in the opencast mine operation occur in the period when mine work achieves project circuits of the opencast mine on the surface. In this period, the width of working areas is cut down, spare reserves are reduced and a tendency to deposit extraction efficiency decrease becomes obvious (Yakubovskiy et al., 2015; Kholodnyakov and Argimbayev, 2014).

This changing ratio of different deposits extraction volumes and mine mass makes a lot of difficulties and causes additional cash expenditure (Bukhman et al., 1966; Kaerbek and Kholodjakov, 2016; Kaerbek and Maya, 2016; Kaerbek and Ivanova, 2016). Annual mine mass output of an opencast mine: 


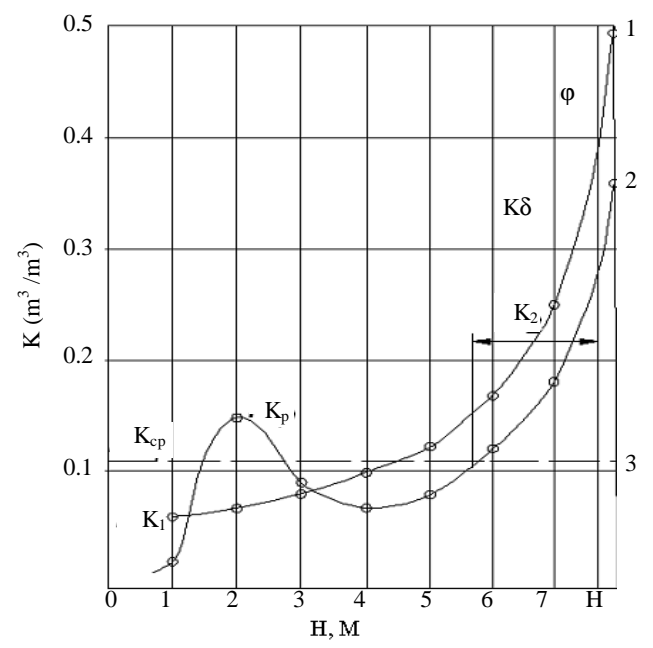

Fig. 2: The change of extraction coefficient after deepening: $\mathrm{K}_{1}$ operational coefficient of extraction in the first period, $\mathrm{m}^{3} / \mathrm{m}^{3}, \mathrm{~K}_{2}$ operational coefficient of extraction in subsequent years, $\mathrm{m}^{3} / \mathrm{m}^{3} ; \mathrm{K}_{\mathrm{T}}$ (line 1) operational coefficient of extraction $\left(\varphi_{0}\right) ; \mathrm{K}_{\mathrm{p}}($ line 2$)$ operational coefficient of extraction $\left(\varphi_{\max }\right), \mathrm{m}^{3} / \mathrm{m}^{3}$; $\mathrm{K}_{\mathrm{cp}}$ (line 3): average operational coefficient of extraction, $\mathrm{m}^{3} / \mathrm{m}^{3}$ and $\varphi$ : angle of slope of the working side, grad

$$
\mathrm{Q}=\mathrm{A}_{1}+\mathrm{A}_{2}+, \ldots,+\mathrm{A}_{\mathrm{n}}+\mathrm{V}=\mathrm{V}+\sum_{\mathrm{i}=1}^{\mathrm{n}} \mathrm{A}_{\mathrm{i}}
$$

Annual mine roche waste output of an opencast mine:

Where:

$$
\mathrm{V}=\left(1-\mathrm{K}_{\partial}\right) \times \mathrm{Q}
$$

$\mathrm{A}_{\mathrm{i}}=$ Annual deposit output of an opencast mine $\left(\mathrm{m}^{3}\right)$

$\mathrm{K}_{\partial}=$ Operational total extraction coefficient $\left(\mathrm{m}^{3} / \mathrm{m}^{3}\right)$

$$
\mathrm{K}_{\sigma}=\mathrm{K}_{1}+\mathrm{K}_{2}+, \ldots,+\mathrm{K}_{\mathrm{n}}=\sum_{\mathrm{i}=1}^{\mathrm{n}} \mathrm{K}_{\mathrm{i}}
$$

where, $\mathrm{K}_{\mathrm{i}}$ is an operational (i) deposit extraction coefficient $\left(\mathrm{m}^{3} / \mathrm{m}^{3}\right)$. One of the main normal working conditions of the opencast mine is the preservation of the sufficient width of working areas on the working bench of the opencast mine for the whole period of time. Their width can be minimized but at the same time there is no reserve of deposits ready for being taken out.

The reduction of working area width to the value lower than maximum permissible leads to the break of usual work of the opencast mine. It is difficult to restart mining work on banks with no working areas.
As shown above at the constant inter-ramp angle the operational extraction coefficient is usually a variable value and this leads to the efficiency reduction and makes the working process more complicated. Thus, the research of the opencast mine only for this case doesn't solve the problem of averaging of the operational extraction coefficient (Argimbaev and Alexandrovich, 2016a; Argimbaev, 2016; Argimbayev et al., 2016).

Similarly to the research of the overburden coefficient (Yakubovskiy et al., 2015) carried out by Arsentjev for averaging extraction coefficient it is advisable to establish the field of possible solutions first of all. For this purpose, we shall consider two extreme cases of the opencast mine development.

Mining work in the opencast mine is carried out on the maximum possible amount of working banks with the preservation of working areas of minimal width. The inter-ramp angle is constant and equal to the maximum permissible $\varphi_{\max }$.

Mining work is carried out only on one working bank till the end and then lowered to the bottom bank prepared in advance, etc. (Argimbayev, 2016). Working areas will be of maximum width and the inter-ramp angle $\varphi_{0}$ will be close to null. The maximum permissible inter-ramp angle is:

$$
\operatorname{tg} \varphi_{\max }=\frac{h}{h \operatorname{ctg} \alpha+B_{\text {min }}}
$$

where, $B_{\min }$ is a minimum permissible width of a working area, $m$ under such conditions. We shall consider the possibility of averaging of the operational extraction coefficient only for the main deposit of complex field mining.

Based on data given in Fig. 3, we can calculate the volumes of deposits and mine mass for two extreme cases mentioned above and we shall make a cumulative graph $\mathrm{p}=\mathrm{f}(\mathrm{Q})\left(\right.$ Fig. 3) for the main $\left(\mathrm{P}_{1}\right)$ deposit of complex field mining.

We point the increasing deposit volume extracted during the opencast mine life-time on the ordinate axis and the increasing volume of mine mass taken out on the axis of abscissas. For cases $\varphi=15^{\circ}$ and for $\varphi \rightarrow 0$ we get two curves. The values of extraction coefficients are shown in Fig. 2 where the extraction coefficient $\mathrm{K}_{\mathrm{r}}$ corresponds to the case $\varphi_{0}$, the former is obviously identical to the horizon extraction coefficient, the latter $\varphi_{\max }$ is the extraction coefficient $\mathrm{K}_{\mathrm{P}}$.

If you stick to any of shown extreme cases when developing the opencast mine, you will have to work all the time with the variable extraction coefficient which is not desirable because by doing so, we have the following results: technical-economical values deteriorate; large amount of equipment and energy volume are 


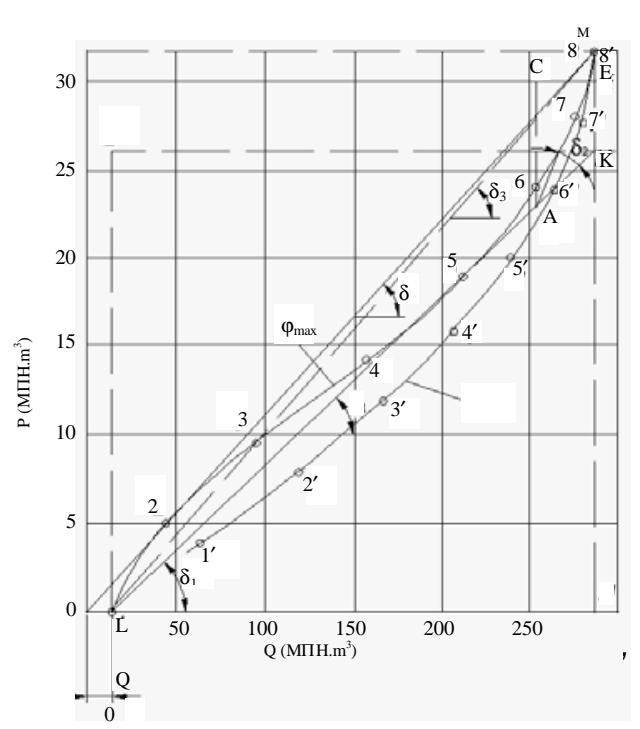

Fig. 3: The change graph of increasing mine mass volume (Q) depending on extracted volume of a deposit (P) when $\varphi \rightarrow 0$ and $\varphi_{\max }: 1.8$ build points; OM: change in the volume of mineral resources; LM: change in rock volumes; LK: long-term work with constant production performance factors; OLAEM: change in actual volume of rock mass; $\varphi$ : angle of slope of the working side, grad; $\varphi_{\max }$ : maximum angle of slope of the working side, grad; $\delta_{\mathrm{i}}$ : angle of inclination of tangent, $\operatorname{grad} \mathrm{MN} / \mathrm{ON}=$ $\operatorname{tg} \delta ; \mathrm{LB} / \mathrm{KB}=\operatorname{tg} \delta_{1} ; \mathrm{AE}=\mathrm{K}_{2}=\operatorname{tg} \boldsymbol{\delta}_{2}$

concentrated for a short period of time; the need in personnel and accommodation fluctuates sharply (Argimbaev, 2016b).

The necessity of planned mode for mining work at stages was proved by the member of the Academy of Sciences Rzhevskiy. He also showed the economical ground for the advisability to averaged extraction work volumes and mine mass taken (Argimbaev and Alexandrovich, 2016).

\section{RESULTS AND DISCUSSION}

We shall pay attention to the special feature of the graph in Fig. 3. The extraction coefficient on the graph is characterized by the slope angle tangent line to the curve $\mathrm{P}=\mathrm{f}(\mathrm{Q})$ at the given point. It means that the work with the constant extraction coefficient must be shown on the graph by means of a straight line. To determine the value of extraction coefficient on the graph $\mathrm{P}=\mathrm{f}(\mathrm{Q})$ we don't need to measure the line slope angle but we have to specify bearings of points at the beginning and end of the period and calculate the ratio $\Delta \mathrm{P} / \Delta \mathrm{Q}$ :

$$
\operatorname{tg} \delta=\frac{\mathrm{MN}}{\mathrm{ON}}=\frac{\mathrm{P}}{\mathrm{Q}}=\mathrm{k}_{\mathrm{cp}}
$$

We can assume that the extraction coefficient will be equal to the average. Then, the change of deposit volume will be shown by the straight line $\mathrm{OM}$ and the line $\mathrm{OM}$ will be lower than the curve for $\varphi_{\max }$ and this means that in certain periods of mining operation some working areas will become too narrow and the slope angle of the working bench will exceed allowable value. Besides during the initial period the operation with operational extraction coefficient equal to the average is absolutely impossible in case of given overburden scheme in Fig. 3 because before the extraction of deposits it is necessary to extract the mine mass volume $\mathrm{Q}_{0}$.

We shall study the possibility to work with the average operational coefficient of extraction. The change of roche volumes will be shown by means of a dotted line LM and the extraction coefficient:

$$
\mathrm{K}_{1}=\operatorname{tg} \delta_{3}=\frac{\mathrm{MN}}{\mathrm{LM}}=\frac{\mathrm{P}}{\mathrm{Q}-\mathrm{Q}_{0}}
$$

The straight line LM when working until mine 3 is below than the line $\mathrm{P}=\mathrm{f}(\mathrm{Q})$ it means the operation is possible but starting from mine 3 the line LM goes higher than the curve and this is a sign of inadmissible reduction of the width of working areas. Consequently, it is impossible to work with the extraction coefficient equal to the average operational one for a long time.

It is obvious that cases with the constant operational coefficient can be expressed by means of straight lines located between curves $P=f(Q)$ when $\varphi_{\max }$ and $\varphi_{0}$. Long-term work with the constant operational extraction coefficient can be expressed by the straight line LK-tangent line to the curve for $\varphi_{\max }$. In this case, the operational extraction coefficient is calculated according to the equation:

$$
\mathrm{K}=\operatorname{tg} \delta_{1}=\frac{\mathrm{LB}}{\mathrm{KB}}
$$

The operational extraction coefficient is connected with the average operational coefficient $\left(\mathrm{K}_{m ? n}\right)$ by the following dependence:

$$
\mathrm{K}=\lambda \mathrm{K}_{\imath ? ?}
$$

where, $\lambda$ is the coefficient of averaging of extraction coefficient in the certain operation period of the opencast mine. 


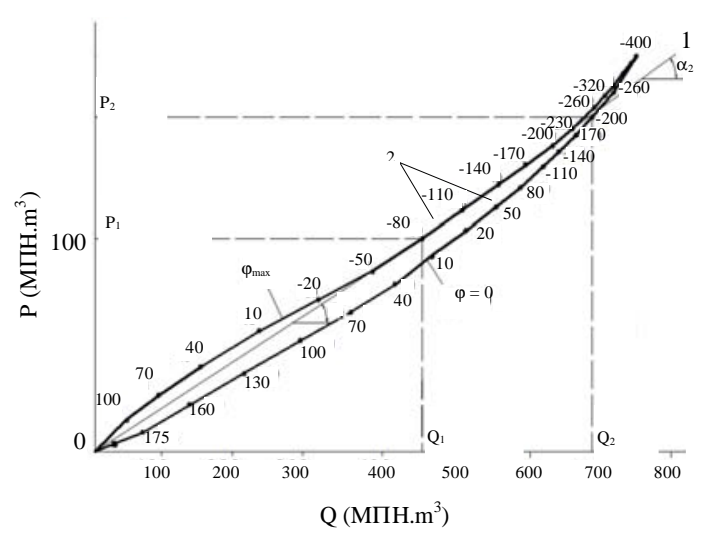

Fig. 4: Dependence of increasing ore volumes on mine mass volumes: $\mathrm{P}$ ore volumes, $\mathrm{mln} \mathrm{m}^{3}$; $\mathrm{Q}$ mine mass volumes, $\mathrm{mln} \mathrm{m}^{3} ; 400, \ldots, 100$ excavation horizons, $m$; $\varphi$ line 1 work career with a stable productivity of ore and rock mass; lines 2 graphics of increasing volumes of ore and rock mass; $\varphi$ angle of slope of the working side, grad; $\varphi_{\max }$ maximum angle of slope of the working side, grad; $\alpha^{i}$ angle of inclination of tangent, grad

The operational extraction coefficient is interconnected with average coefficient $\left(\mathrm{K}_{\mathrm{cp}}\right)$ by the dependence:

$$
\mathrm{K}=\frac{\lambda \mathrm{K}_{\mathrm{cp}}}{1-\mu}
$$

where, $\mu$ is a percent of pre-overburden work in the total volume of mine mass. When working with the extraction coefficient expressed by means of a straight line, inter-ramp angle during the operation period will have a variable value and will not exceed $\varphi_{\max }$ but the width of working areas will not be less than minimal permissible, i.e., all the standards of mining production conditions will be observed in the opencast mine.

As you can see in Fig. 4 when mining work with the extraction coefficient like $\mathrm{K}_{1}=\operatorname{tg} \delta_{1}$, reaches bank 6 , the inter-ramp angle will be close to null because the straight line meets the curve for $\varphi \rightarrow 0$ at this point. If they continue working with the same extraction coefficient then they will have to deepen the opencast mine according to hanging wall roche, i.e., they will have to change the method of overburden. In most cases it is not advisable and sometimes it is just impossible.

Therefore, it is not desirable that straight lines characterizing the mining work with averaged operational extraction coefficient are located lower than the curve for $\varphi_{0}$. Starting from bank 5 and deeper it is advisable to increase the operational extraction coefficient up to $\mathrm{K}_{2} \operatorname{tg} \delta_{2}$ (straight line $\mathrm{AE}$ ).
By the end of the opencast mine development it is possible to work with the variable value of the operational extraction coefficient. It means that the change of mine mass real volume is advisable to be carried out in accordance with the broken line OLAEM.

During the first period they can work with the operational extraction coefficient $\mathrm{K}_{1}=0.1 \mathrm{~m}^{3} / \mathrm{m}^{3}$ but during next years with $\mathrm{K}_{2}=22 \mathrm{~m}^{3} / \mathrm{m}^{3}$ (Fig. 3 and 4). However, the averaged coefficients for the given example are equal:

$$
\begin{aligned}
& \lambda_{1}=\frac{0.1}{0.12}=0.8 \\
& \lambda_{2}=\frac{0.22}{0.12}=1.83
\end{aligned}
$$

All possible variants of mining work are not limited by the given values of extraction coefficients and working periods of the opencast mine. They can also work in accordance with many broken lines which you can see between curves for $\varphi_{0}$ and $\varphi_{\max }$ and you can divide the mining work into many stages. By doing so, you should bear in mind technical-economical parameters.

The curve for $\varphi_{\max }$ is valid only for one variant of mining work mode. If you change the direction of deepening (method of overburden) and the direction of front moving then you will have to make another curve. The curve for $\varphi_{0}$ will be the same for all possible variants of mining development in case the final configuration of the opencast mine is not changed.

The cumulative graph $\mathrm{P}=\mathrm{f}(\mathrm{Q})$ allows to find $\mathrm{a}$ possible area for changing deposit and mine mass volumes and to make a correct decision how to determine the value of averaged extraction coefficients and how to separate the field mining into different periods.

Under certain conditions the choice of working periods with the constant extraction coefficient is limited by curves for $\varphi_{0}$ and $\varphi_{\max }$ and often it is not acceptable due to a designer. In many cases the duration of such stages is fairly made up depending on the conditions of deposit positions and can't be changed in the wide range.

We should always bear in mind that the further the recommended line $P=f(Q)$ is from the line $\varphi_{\max }$ and closer to the line for $\varphi_{0}$ the lower is the number of working banks it means that the possible output of the opencast mine is reduced. Therefore, in some cases after checking for the output it is necessary to make certain the operational extraction coefficient.

The project practice shows that due to various conditions of deposit positions, methods of overburden and development systems the curves for two cases in question cannot always give a chance to establish a 
possible area of changing the function $P=f(Q)$ for sure, especially in cases when these two curves intercross or are located too close to each other. On the basis of such data we made a graph $\mathrm{P}=\mathrm{f}(\mathrm{Q})$ of increasing ore and mine mass volumes for the iron-ore opencast mine in Kostomuksha (Fig. 4).

The operation of the opencast mine with the stable ore and mine mass output is characterized by means of a straight line on the graph whose slope to the horizon is the operational extraction coefficient.

After analyzing the graph we can divide the operation of the opencast mine into two stages with different operational extraction coefficients $(\mathrm{K})$.

1st stage of a field mining development:

$$
\mathrm{K}_{1}=\frac{109.8}{448.6}=0.24_{\mathrm{m}^{3} / \mathrm{m}^{3}}=0.27 \mathrm{~m} / \mathrm{m}
$$

2nd stage of a field mining development:

$$
\mathrm{K}_{2}=\frac{60.2}{2340}=0.26_{\mathrm{m}^{3} / \mathrm{m}^{3}}=0.29 \mathrm{~m} / \mathrm{m}
$$

\section{CONCLUSION}

We considered the methods to determine the average operational extraction coefficient by using one cut in the mining field. It is a common practice to establish the operational coefficient for the whole opencast mine in projects. One can use different means for this purpose: cross cut on the mining field, horizon plans, weighted cross cut on the mining field, modelling mine work, analytical calculations.

We made a calculation of operational extraction coefficient for the iron-ore opencast mine in Kostomuksha by using horizon plans. Each of these plans contains information about volumes of ore and mine mass to provide preparations of every bottom horizon with respect to used direction of mine work development. According to the calculation results it became clear that the development of this field mining can be divided into 2 stages with operational extraction coefficients of 0.27 tonn/tonn and 0.29 tonn/tonn correspondingly.

\section{REFERENCES}

Argimbaev, K.R. and H.A. Kholodjakov, 2013. Determining the safe working height of an power shovel for the development of iron-bearing tailing dumps. World Appl. Sci. J., 27: 1087-1090.

Argimbaev, K.R. and H.A. Kholodjakov, 2015. Erection methods and constructions of primary tailing dike. Intl. J. Ecol. Develop., 30: 47-54.
Argimbaev, K.R. and H.A. Kholodjakov, 2016. Tailings development and their utilization in the national economy. Int. J. Ecol. Dev., 31: 94-100.

Argimbaev, K.R. and I.V. Alexandrovich, 2016. Measuring the optimal focal distance to make Initial cavity in the mass of solid natural resources. Res. J. Appl. Sci., 11: 240-244.

Argimbaev, K.R. and M.M. Yakubovskiy, 2014. Economic substantiation of a quarry usage and an overburden dumps, considering the disposal of industrial waste in them. World Appl. Sci. J., 29: 1621-1625.

Argimbaev, K.R., 2016a. Monitoring of the industrial process impact on the environment in an open pit. Int. J. Ecol. Dev., 31: 23-28.

Argimbaev, K.R., 2016b. Monitoring of air and water near quarries and measures to mitigate environmental impact. Intl. J. Ecol. Econ. Stat., 37: 119-126.

Argimbaev, K.R., M.M. Yakubovskiy and M.A. Ivanova, 2015. Design justification of drainage and anti filter facilities of the tailings at various methods of their constructions. Intl. J. Ecol. Develop., 30: 76-85.

Argimbayev, K.R., 2016. Assessment of the stress-strain state of the foliated cutoff mass. Intl. J. Ecol. Dev., 31: 68-77.

Argimbayev, K.R., M.O. Bovdui and K.V. Mironova, 2016. Prospects for exploitation of tailing dumps. Int. J. Ecol. Dev., 31: 117-124.

Bukhman, I., P.G. Simakov, A.S. Argimbaev and S.V. Beliaev, 1966. Removal of dust from the air of an excavator operator's cabin. Gigiena Sanitariia, 31: 96108.

Kaerbek, R.A. and B.O. Maya, 2016. The experience of the introduction of mobile crushing and screening complexes on a deposit of building materials. Res. J. Appl. Sci., 11: 300-303.

Kaerbek, R.A. and H.A. Kholodjakov, 2016. Development of numerical models for rock mass stress-strain behavior forecasting during ore deposit open-pit mining. Res. J. Appl. Sci., 11: 281-286.

Kaerbek, R.A. and M.A. Ivanova, 2016. Calculation coefficient of strength decrease of the rock mass fragments in the shotpile. Res. J. Appl. Sci., 11: $245-250$.

Kholodjakov, H.A. and K.R. Argimbaev, 2014. Waste storage feasibility of concentrating mill in overburden dumps. World Appl. Sci. J., 30: 738-740.

Kholodnyakov, G.A. and K.R. Argimbayev, 2014. The choice and substantiation of the technological parameters of tailing formation in an overburden dump body. Scientific Bull. National Mining Univ., 2: $50-57$. 
Pashkevich, M.A. and T.A. Petrova, 2015. The investigation of toxic waste burial polygon impact on the atmospheric air using lichenoindication method (Russia). Intl. J. Ecol. Dev., 30: 98-105.

Pikalov, V.A., A.V. Sokolovsky, V.N. Vasilets and K.V. Burmistrov, 2016. Substantiation of efficient parameters for hybrid open pit-underground mining of coal. Gornyi Zhurnal, 1: 67-72.
Yakubovskiy, M.M., K.R. Argimbaev and M.A. Ivanova, 2014. Investigation of the quarry transfer points influence on reduction of mining operations. World Appl. Sci. J., 30: 1401-1403.

Yakubovskiy, M.M., K.R. Argimbaev and M.A. Ivanova, 2015. Constructions investigation of ore transfer points within mining limits while developing the deep pit. Intl. J. Ecol. Dev., 30: 83-87. 